\title{
APLIKASI FUZZY LOGIC UNTUK PENGENDALIAN MOTOR COMPRESSOR PADA AIR CONDITIONER BERBASIS ATMEGA8535
}

\author{
Elfizon*, Asnil ${ }^{* *}$ \\ Teknik Elektro Fakultas Teknik \\ Universitas Negeri Padang (UNP) \\ Email: ")elfizon24@gmail.com, ${ }^{* *)}$ asnil81@gmail.com
}

\begin{abstract}
Abstrak
Peneltian ini bertujuan untuk mengendalikan AC kompresor motor dengan aplikasi logika fuzzy berbasis ATMega8535. Sensor SHT11 digunakan untuk mendeteksi suhu dan sensor inframerah untuk menghitung jumlah orang di dalam ruangan. Alat ini dilengkapi dengan PC sebagai respon penampil suhu dan LCD penampil tempertature dan jumlah orang yang masuk dan keluar ruangan. Ia bekerja sesuai dengan parameter yang dirancang dari setiap komponen di sirkuit. Dalam pengujian perangkat keras dan perangkat lunak, diketahui bahwa kompresor sistem kontrol motor bisa menghemat energi karena tegangan yang masuk ke motor kompresor tidak sepenuhnya di 220 volt tetapi sesuai dengan program yang telah di-download di mikroconroller. Untuk mendapatkan pengaturan yang lebih baik, kecepatan motor kompresor perlu ditingkatkan berdasarkan jumlah orang dan suhu ruangan terdeteksi.
\end{abstract}

Kata kunci: Fuzzy Logic, motor Induksi 1 fasa, Mikrokontroller ATMega 8535, Sensor SHT11, Sensor IR

\section{Pendahuluan}

Tidak dapat dipungkiri bahwa kebutuhan manusia akan alat pendingin ruang atau lebih dikenal dengan sebutan AC (Air Conditioner) semakin meningkat, khususnya dalam bidang industri, perkantoran, bahkan pada lingkup kecil seperti rumah tangga.

Pendingin ruangan atau AC memiliki banyak sekali variasi, fungsi, dan bentuk, yang dalam hal ini disesuaikan pada bentuk dan kapasitas besarnya ruangan yang akan menggunakan fasilitas pendingin ruangan tersebut. Salah satu variasinya adalah AC yang menggunakan remote control dalam mengatur temperatur ruangan yang dikehendaki. Sehingga temperatur standar yang diinginkan dapat diubah-ubah karena adanya keinginan tiap individu yang sedang beraktivitas didalam ruangan tersebut. Namun sayangnya, penggunaan AC justru dapat mengakibatkan penggunaan energi listrik menjadi tidak efisien. Hal ini karena oleh sebagian orang, AC digunakan tidak sesuai dengan kebutuhan mereka. Misalnya, AC dibiarkan dalam kondisi ON meski suhu ruang bisa dikatakan tidak panas, atau setting AC tidak sesuai dengan suhu ruang. Dengan kata lain nantinya pengeluaran biaya beban yang disebabkan konsumsi penggunaan $\mathrm{AC}$ tersebut menjadi tidak efisien.

Oleh karena itu dalam penelitian ini dirancang kontroller AC berbasis ATMega8353 menggunakan metode fuzzy logic yaitu sebuah pendingin ruangan dengan otomatisasi penggunaan listrik untuk tujuan efisiensi, maka diharapkan ruangan akan menjadi lebih nyaman dan hemat dari penggunaan energi listrik. Tujuan dari perancangan ini adalah untuk mengendalikan motor compressor yang ada pada AC agar suhu dalam ruangan tetap stabil sesuai dengan temperatur yang telah ditetapkan.

Sistem kendali adalah hubungan antara komponen yang membentuk sebuah konfigurasi sistem yang akan menghasilkan tanggapan sistem yang diharapkan.

\section{Logika Fuzzy}

Menurut Son Kuswadi (2007:20) “Fuzzy set pertama kali diperkenalkan oleh Prof. Lotfi Zadeh, 1965, dalam papernya yang monumental." Prof. Lotfi Zadeh adalah seorang profesor di University of California di Berkeley. Logika fuzzy menawarkan alternatif lain dalam perancangan dimana aksi kontrolnya dinyatakan dengan ungkapan bahasa, bukan menggunakan nilai - nilai tajam (crisp) seperti pada aksi kontrol konvensional.

Pada teori himpunan klasik yang disebut juga dengan himpunan crisp (himpunan tegas) hanya dikenal dua kemungkinan dalam fungsi keanggotaannya, yaitu kemungkinan termasuk keanggotaan himpunan (logika 1) atau kemungkinan berada di luar keanggotaannya (logika 0 ). Namun dalam teori himpunan fuzzy tidak hanya memiliki dua kemungkinan dalam menentukan sifat 
keanggotaannya tetapi memiliki derajat kenaggotaan yang nilainya antara 0 dan 1 . fungsi yang menetapkan nilai ini dinamakan fungsi keanggotaan yang disertakan dalam himpunan fuzzy

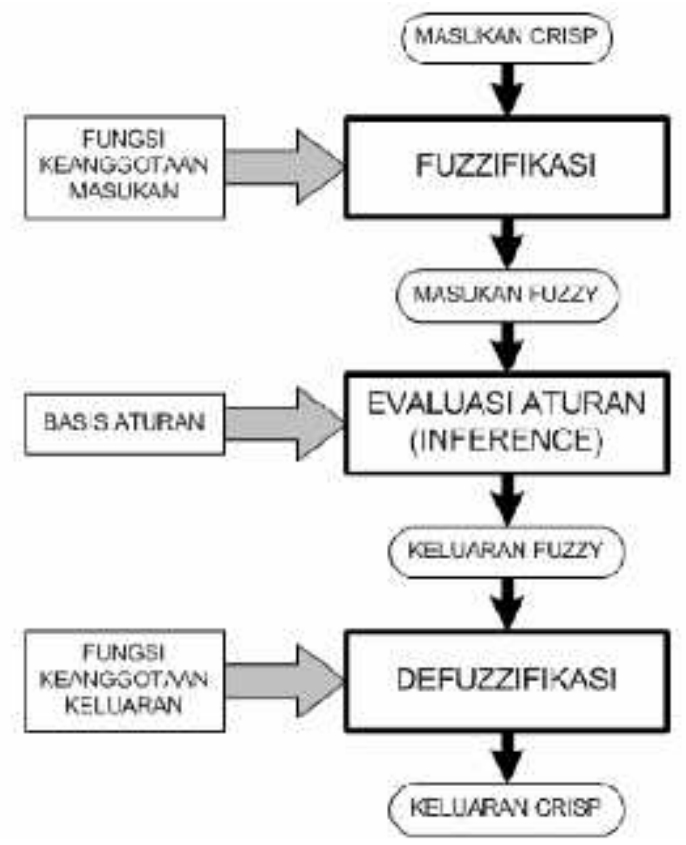

Gambar 1. Struktur Dasar Pengendali Fuzzy

(Sri Kusumadewi, 2004: 10)

\section{Mikrokontroler Atmega 16}

Atmega 16 merupakan seri mikrokontroler CMOS 8-bit buatan Atmel, berbasis arsitektur RISC (Reduced Instruction Set Computer). Hampir semua instruksi dieksekusi dalam satu siklus clock. AVR mempunyai 32 register general-purpose, timer/counter fleksibel dengan mode compare, interrupt internal dan eksternal, serial UART, programmable Watchdog Timer, dan mode power saving, ADC dan PWM internal. AVR juga mempunyai In-System Programmable Flash on-chip yang mengijinkan memori program untuk diprogram ulang dalam sistem menggunakan hubungan serial.

\section{Motor Induksi satu fasa}

Motor induksi satu fasa merupakan salah satu jenis motor AC. Prinsip kerjanya menggunakan induksi elektromagnetik dengan terlebih dahulu membentuk medan putar pada stator, medan putar tersebut akan menginduksi rotor motor induksi karena rotor motor induksi, karena rotor merupakan rangkaian tertutup maka terdapat arus pada rotor, interaksi antara medan putar stator dengan arus rotor akan membuat rotor berputar.

\section{Driver Motor}

Jenis optocoupler yang digunakan adalah optocoupler MOC3021. Optocoupler ini dipakai sebagai peralatan proteksi untuk melindungi rangkaian pengatur penyalaan thyristor. Dimana optocoupler dicatu oleh transistor pada rangkaian kontrol sehingga optocoupler tersebut memicu tegangan gate pada Triac.

\section{Metode Perancangan Alat}

Perancangan merupakan suatu tahapan dari proses dalam pembuatan alat. Perancangan alat digunakan untuk menentukan komponen penyusunan dari suatu alat yang akan dibuat, sehingga hasil akhirnya sesuai dengan yang diinginkan. Perancangan terdiri dari pembuatan diagram blok dan sketsa rangkaian untuk setiap blok dengan fungsi tertentu dan spesifikasi alat yang diharapkan. Setiap blok dihubungkan sehingga terbentuk sistem alat yang diharapkan.

\section{Blok Diagram}

Pada perancangan alat ini, sistem secara keseluruhan dapat dilihat pada gambar dibawah ini.

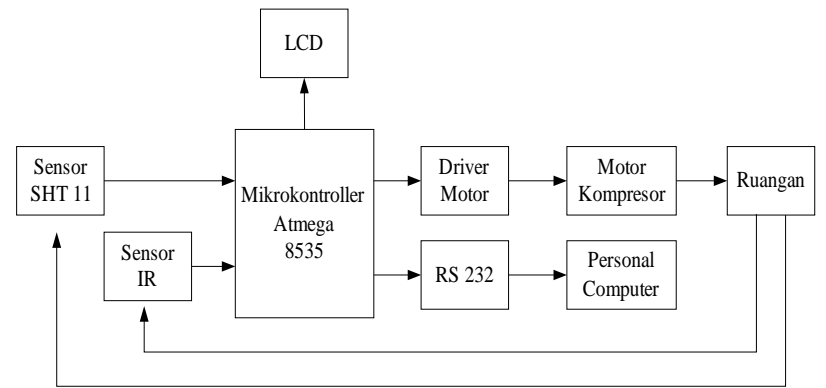

Gambar 2. Blok Diagram Sistem Pengendalian Motor Compressor pada AC

Komponen yang digunakan dalam perancangan ini adalah 2 parameter input yaitu jumlah orang dalam ruangan dan suhu ruangan serta 1 parameter output yaitu kecepatan motor compressor. Dalam aplikasi ini sensor yang digunakan untuk mengcounter jumlah orang dalam ruangan adalah sensor IR yang diletakkan di pintu ruangan sedangkan untuk mengukur suhu ruangan digunakan sensor SHT11 yang memiliki tingkat kepresisian yang bagus. Semua parameter tersebut diinputkan pada sebuah kontroller Atmega8535 dan output dari kontroller di umpankan untuk mengatur kecepatan dari motor compressor.

Sistem utama pada alat ini diatur oleh mikrokontroler ATMega8535 dengan menggunakan bahasa pemograman yaitu BASCOM. Mikrokontroler ATMega8535 ini terkoneksi dengan sensor IR dan sensor SHT11 sebagai pendeteksi orang dan suhu di dalam ruangan. Kemudian respon dari alat ini akan ditampilkan melalui PC.

\section{Perancangan Perangkat Keras}

Perancangan hardware merupakan hal yang sangat penting dalam penelitian ini. Karena dengan adanya hardware barulah sistem dapat diuji secara nyata apakah alat ini dapat bekerja dengan baik atau tidak. 


\section{Sensor Suhu}

Sensor SHT11 terdiri dari 4 pin diantaranya adalah GND, Vdd (5V), Serial data dan serial cloAC. Pin 1 dihubungkan pada kaki ground, pin 2 memberi serial data yang dihubungkan ke PA1 mikrokontroler, untuk pin 3 memberi serial cloAC yang dihubungkan ke PA0 mikrokontroler, sedangkan pada pin 4 adalah VDD yaitu sumber arus yang dialirkan pada sensor SHT11. Sensor ini berfungsi untuk mendeteksi suhu didalam ruangan.

\section{Sensor IR}

Sensor IR merupakan sensor yang digunakan untuk menghitung jumlah orang di dalam ruangan. Sensor ini akan di letakkan pada pintu masuk, sehingga jika ada benda yang melintasi sensor ini, sensor akan menghitung setiap benda yang melintasinya. Sensor IR ini menggunakan LM358 sebagai penguatnya. IR1 terhubung ke PB0 pada mikrokontroler dan IR2 terhubung ke PB1 pada mikrokontroller.

\section{LCD}

Penampil pada sistem pegendalian ini menggunakan modul penyaji kristal cair (LCD) dengan tingkat kecerahan tinggi. Modul ini merupakan modul penyaji kristal cair matrik titik dengan pengendali di dalamnya. Pengendali ini mempunyai sebuah ROM/RAM pembangkit karakter di dalamnya dan RAM data tampilan. Semua fungsi tampilan dikendalikan oleh instruksi-instruksi. LCD ini dihubungkan ke PORD C pada mikrokontroller.

PC digunakan untuk melihat respon dari system ini. Respon yang akan ditampilkan adalah respon dari suhu di dalam ruangan. Untuk menghubungkan PC ke rangkaian control makan diperlukan suatu interface, interface yang digunakan dalam rangkaian ini adalah RS 232 dengan IC Max 232. Kaki ke 9 pada IC Max 232 dihubungakan pada port D0 pada mikrokontroller dan kaki 10 dihubungkan dengan port D1. Kaki 7 dan kaki 8 pada IC Max 232 akan dihubungkan pada DB 9, kemudian DB 9 inilah yang nantinya akan dihubungkan pada PC. Software yang digunakan untuk melihat respon pada PC adalah Visual Basic 6.0.

\section{Perancangan Perangkat Lunak}

Pada perancangan software ini terdiri dari diagram alur (flowchart). Flowchart berfungsi sebagai acuan dalam membuat listing program.

Pada flowchart berisi penentuan instruksi-instruksi dari program yang akan dibuat. Flowchart dapat menunjukan secara jelas arus pengendalian algoritma, yaitu bagaimana rangkaian pelaksanaan kegiatan. Kemudian dilanjutkan dengan perancangan Fuzzy Logic.

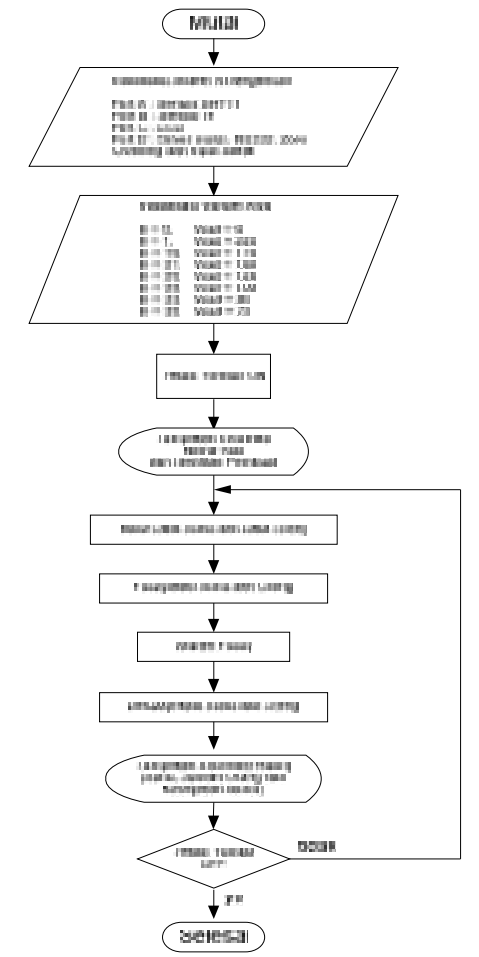

Gambar 3. Diagram Alir (Flow Chart) Sistem Pengendali Motor Compressor pada AC

\section{Perancangan Logika Fuzzy}

Sistem inferensi fuzzy yang digunakan pengendali penerangan ruangan ini adalah Metode Mamdani. Pada metode mamdani, untuk mendapatkan output diperlukan 4 tahapan, yaitu: Pembentukan himpunan fuzzy (fuzzifikasi), aplikasi fungsi implikasi (aturan), komposisi aturan, dan penegasan (defuzzifikasi). Komposisi aturan menggunakan operator OR (union), sedangkan untuk defuzzifikasi digunakan metode Centroid.

Tabel 1. Variabel Input Suhu

\begin{tabular}{lll}
\hline No & Scope & Label \\
\hline 1 & $\leq 16^{\circ} \mathrm{C}$ & Sangat Dingin \\
\hline 2 & $16^{\circ} \mathrm{C} \mathrm{s} / \mathrm{d} 20^{\circ} \mathrm{C}$ & Dingin \\
\hline 3 & $21^{\circ} \mathrm{C} \mathrm{s} / \mathrm{d} 25^{\circ} \mathrm{C}$ & Normal \\
\hline 4 & $26^{\circ} \mathrm{C} \mathrm{s} / \mathrm{d} 30^{\circ} \mathrm{C}$ & Panas \\
\hline 5 & $31^{\circ} \mathrm{C} \mathrm{s} / \mathrm{d} 35^{\circ} \mathrm{C}$ & Sangat Panas \\
\hline
\end{tabular}

Tabel 2. Variabel Input Jumlah Orang

\begin{tabular}{lll}
\hline No & Scope & Label \\
\hline 1 & $\leq 5$ orang & Sedikit \\
\hline 2 & 0 s.d 10 orang & Sedang \\
\hline 3 & 5 s.d 15 orang & Banyak \\
\hline 4 & 10 s.d 20 orang & Banyak Sekali \\
\hline 5 & 215 orang & Penuh \\
\hline
\end{tabular}

Output yang berupa nilai tegas (crisp) difuzzyfikasi menjadi himpunan-himpunan fuzzy SANGAT LAMBAT, LAMBAT, AGAK CEPAT, CEPAT, dan SANGAT CEPAT. 
Tabel 3. Variabel Kecepatan Motor (Output)

\begin{tabular}{lll}
\hline No & Scope & Label \\
\hline 1 & $110 \mathrm{~V}$ & Sangat Lambat \\
\hline 2 & $140 \mathrm{~V}$ & Lambat \\
\hline 3 & $170 \mathrm{~V}$ & Agak Cepat \\
\hline 4 & $190 \mathrm{~V}$ & Cepat \\
\hline 5 & $220 \mathrm{~V}$ & Sangat Cepat \\
\hline
\end{tabular}

Tabel 4. Aturan Fuzzy Untuk Sistem Pengendalian Motor Kompressor

Keterangan Tabel :

$\mathrm{SL}=$ Sangat Lambat

$\mathrm{L}=$ Lambat

$\mathrm{AC}=$ Agak Cepat

$\mathrm{CP}=$ Cepat

$\mathrm{SC}=$ Sangat Cepat

\section{Hasil dan Pembahasan}

\section{Pengujian Sensor SHT11}

Untuk dapat mengetahui tingkat ketelitian alat dalam pengujian ini maka harus dilakukan pengujian terhadap sensor dengan cara membandingkan hasil sensor tersebut dengan alat ukur. Jika nilai suhu yang ditampilkan sesuai dengan alat ukur yang telah terkalibrasi, berarti modul sensor SHT11 dan program pengujiannya sudah bekerja dengan baik. Hasil pengujian dapat dilihat pada Tabel.

Tabel 5. Hasil Pengujian Modul SHT 11

\begin{tabular}{llll}
\hline $\begin{array}{l}\mathbf{N} \\
\text { (Orang) }\end{array}$ & $\begin{array}{l}\text { Modul Sensor } \\
\text { SHT11 } \\
(\mathbf{} \mathbf{c})\end{array}$ & $\begin{array}{l}\text { Alat Ukur } \\
\text { untuk } \\
\text { Kalibrasi } \\
\mathbf{(} \mathbf{c})\end{array}$ & Kecepatan \\
\hline 1 & 32,69 & 32,77 & Lambat \\
\hline 3 & 32,69 & 32,77 & Lambat \\
\hline 5 & 32,72 & 32,80 & Lambat \\
\hline 7 & 32,79 & 32,88 & Agak Cepat \\
\hline 10 & 32,79 & 32,88 & Agak Cepat \\
\hline 13 & 32,85 & 33,92 & Agak Cepat \\
\hline 15 & 32,88 & 33,95 & Agak Cepat \\
\hline 17 & 32,90 & 32,99 & Cepat \\
\hline 20 & 32,93 & 33,01 & Cepat \\
\hline
\end{tabular}

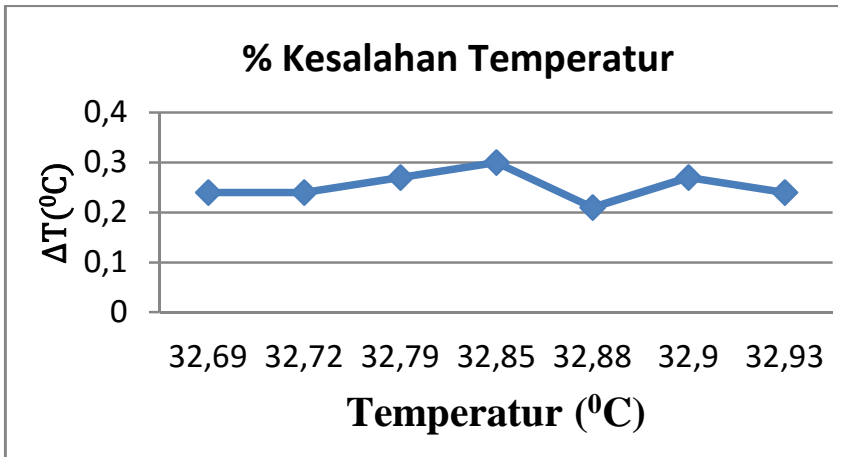

Gambar 7. Grafik Persentase Kesalahan Suhu

\section{Pengujian Sensor Infrared}

Tabel 6. Perbandingan Hasil Pengukuran Sensor

Inframerah dengan Datasheet

\begin{tabular}{|c|c|c|c|c|c|}
\hline \multirow[t]{2}{*}{ No } & \multicolumn{2}{|c|}{$\begin{array}{l}\text { Berdasarkan } \\
\text { pengukuran }\end{array}$} & \multicolumn{3}{|c|}{ Berdasarkan Datasheet } \\
\hline & $\begin{array}{l}\text { Vo saat } \\
\text { tak } \\
\text { terpantul } \\
\text { inframerah }\end{array}$ & $\begin{array}{l}\text { Vo saat } \\
\text { terpantul } \\
\text { inframerah }\end{array}$ & $\begin{array}{l}\text { Vo saat } \\
\text { tak } \\
\text { terpantul } \\
\text { inframerah }\end{array}$ & $\begin{array}{l}\text { Vo } \\
\text { terpantul } \\
\text { inframerah }\end{array}$ & saat \\
\hline 1 & $4,93 \mathrm{~V}$ & $0,04 \mathrm{~V}$ & $5 \mathrm{~V}$ & $0 \mathrm{~V}$ & \\
\hline 2 & $4,90 \mathrm{~V}$ & $0,06 \mathrm{~V}$ & $5 \mathrm{~V}$ & 0 & \\
\hline
\end{tabular}

\section{Analisa Pemakaian Listrik}

Untuk pemakaian biasa :

Dik : $\quad \mathrm{V}=220 \mathrm{~V}$

$$
\mathrm{I}=2,8 \mathrm{~A}
$$

Diasumsikan $\operatorname{Cos} \theta=0,8$

Dit : Berapa biaya listrik yang dikeluarkan dalam 1 bulan (30 hari) jika diambil rata-rata pemakaian AC sehari adalah 10 jam ?

Jawab : $P=$ V.I $\cos \theta=220.2,8.0,8=492,8 \mathrm{~W}$ $\mathrm{E}=\mathrm{P} . \mathrm{t}=492,8.10=4928 \mathrm{Wh}=4,928 \mathrm{kWh}$ Biaya listrik = E x Rp. 893,-

$$
=928 \times \text { Rp. } 893,-
$$

$$
=\text { Rp. 4.400,7 /hari }
$$

Biaya listrik 1 bulan

$$
=\text { Rp. 4.400,7 x } 30 \text { hari }
$$$$
=\text { Rp. 132.021,-/bulan }
$$

Untuk pemakaian setelah menggunakan kontroller ATMega8535 :

Dik : $\quad \mathrm{V}_{1}=110 \mathrm{~V}$

$\mathrm{V}_{2}=140 \mathrm{~V}$

$\mathrm{V}_{3}=170 \mathrm{~V}$

$\mathrm{V}_{4}=190 \mathrm{~V}$

$\mathrm{V}_{5}=220 \mathrm{~V}$

$$
\mathrm{I}=2,8 \mathrm{~A}
$$

Diasumsikan $\operatorname{Cos} \theta=0,8$

Dit : Berapa biaya listrik yang dikeluarkan dalam 1 bulan (30 hari) jika diambil rata-rata pemakaian AC sehari adalah $\mathrm{t}_{1}=\mathrm{t}_{2}=\mathrm{t}_{3}=\mathrm{t}_{4}=\mathrm{t}_{5}=2$ jam?

Jawab : $P_{1}=V_{1}$.I $\operatorname{Cos} \theta=110$. 2,8 . 0,8 $=246,4 \mathrm{~W}$ $\mathrm{E}_{1}=\mathrm{P}_{1} \cdot \mathrm{t}_{1}=246,4.2=492,8 \mathrm{Wh}$

$\mathrm{P}_{1}=\mathrm{V}_{1} . \mathrm{I} \operatorname{Cos} \theta=140.2,8.0,8=313,6 \mathrm{~W}$ $\mathrm{E}_{1}=\mathrm{P}_{1} \cdot \mathrm{t}_{1}=313,6.2=627,2 \mathrm{Wh}$

$\mathrm{P}_{1}=\mathrm{V}_{1} . \mathrm{I} \operatorname{Cos} \theta=170.2,8.0,8=380,8 \mathrm{~W}$ $\mathrm{E}_{1}=\mathrm{P}_{1} \cdot \mathrm{t}_{1}=380,8.2=761,6 \mathrm{Wh}$

$\mathrm{P}_{1}=\mathrm{V}_{1} . \mathrm{I} \operatorname{Cos} \theta=190.2,8.0,8=425,6 \mathrm{~W}$ $\mathrm{E}_{1}=\mathrm{P}_{1} . \mathrm{t}_{1}=425,6.2=851,2 \mathrm{Wh}$

$\mathrm{P}_{1}=\mathrm{V}_{1} . \mathrm{I} \operatorname{Cos} \theta=220.2,8.0,8=492,8 \mathrm{~W}$ $\mathrm{E}_{1}=\mathrm{P}_{1} . \mathrm{t}_{1}=492,8.2=982,6 \mathrm{Wh}$ $\mathrm{E}$ total $=\mathrm{E}_{1}+\mathrm{E}_{2}+\mathrm{E}_{3}+\mathrm{E}_{4}+\mathrm{E}_{5}$ $=492,8+627,2+761,6+851,2+982,6$ $=3717,4 \mathrm{~W}$

$=3,7174 \mathrm{~kW}$

Biaya listrik = E total $\times$ Rp. 893,$=3,7174$ x Rp. 893, $=$ Rp. 3.319,6 /hari 
hari

Biaya listrik 1 bulan $=\operatorname{Rp} \cdot 3 \cdot 319,6 \times 30$

= Rp. 99.588,-/bulan

Dari analisa di atas dapat dilihat perbandingan pembayaran listrik menggunakan kontroller ATMega8535 dan tanpa menggunakan kontroller ATMega8535 dengan selisih pembayaran sebagai berikut :

\begin{tabular}{ll}
\hline $\begin{array}{l}\text { Biaya Listrik tanpa } \\
\text { menggunakan kontroller }\end{array}$ & $\begin{array}{l}\text { Biaya Listrik setelah } \\
\text { menggunakan kontroller }\end{array}$ \\
\hline Rp. 132.021,- & Rp. 99.588,- \\
\hline
\end{tabular}

Selisih biaya pemakaian listrik adalah : Rp. 132.021 - Rp. $99.588=$ Rp. 32.433,-

\section{Penutup}

\section{Kesimpulan}

Motor compressor dikendalikan dengan menggunakan metode logika fuzzy dan mikrokontroller ATMega8535 sebagai kontrollernya berdasarkan perubahan temperatur dan jumlah orang di dalam ruangan.

Dengan menggunakan metoda logika fuzzy penggunaan daya listrik menjadi lebih hemat Rp. 32.433,- karena motor compressor tidak selalu bekerja dalam keadaan $O N-O F F$ melainkan dapat bekerja SANGAT LAMBAT, LAMBAT, AGAK CEPAT, CEPAT, dan SANGAT CEPAT sesuai dengan program yang telah di downloadkan ke mikrokontroller.

\section{Saran}

Dalam penelitian ini, penulis menyadari banyaknya kekurangan yang ditemukan.
Berikut beberapa saran yang diharapkan dapat bermanfaat untuk mengembangkan aplikasi ini diantaranya adalah:

a. Untuk memperoleh kerja sistem yang lebih baik, maka dapat dicoba dengan mengubah dan mengatur basis aturan serta fungsi keanggotaan pada pengendali logika Fuzzy.

b. Sebaiknya gunakan sensor yang lebih sensitif untuk membaca temperatur di dalam ruangan agar sistem dapat bekerja dengan baik.

\section{Referensi}

[1] Afrie Setiawan. 2011. Mikrokontroler ATMEGA 8535 dan ATMEGA 16 menggunakan BASCOM - AVR. Andi: Yokyakarta.

[2] Ali Hamzah. 2011. Analisis Pengendali Kecepatan Motor DC dengan Metoda Logika Fuzzy Berbasis Mikrokontroller Atmega8535. Tugas Akhir. Padang: Jurusan Teknik Elektro UNP.

[3] ATMEL. 2006. Datasheet AVR ATmega8535.(online) (www.alldatashet.com.) Diakses 2 Juli 2012.

[4] Katsuhiko Ogata. 1995. Teknik Kontrol Automatic (Edi Leksono. Terjemahan). Erlangga: Jakarta.

[5] Netika Purwaningrum. 2007. Aplikasi Fuzzy Logic Untuk Pengendali Penerangan Ruangan Berbasis Mikrokontroler Atmega8535. Skipsi. Semarang: Jurusan Teknik Elektro UNS.

[6] Son Kuswadi. 2007. Kendali Cerdas. ANDI: Yogyakarta.

[7] Sri Kusumadewi \& Hari Purnomo. 2004. Aplikasi Logika Fuzzy Untuk pendukung Keputusan. Graha Ilmu .Yogyakarta.

[8] Syahrul. 2012. Mikrokontroler AVR ATMega8535. Informatika: Bandung.

[9] Universitas Negeri Malang. 2000. Pedoman Penulisan Karya Ilmiah. Universitas Negeri Malang: Malang 